\title{
Protein Sorting to Mitochondria: Evolutionary Conservations of Folding and Assembly
}

\author{
Franz-Ulrich Hartl* and Walter Neupert
}

\begin{abstract}
According to the endosymbiont hypothesis, mitochondria have lost the autonomy of their prokaryotic ancestors. They have to import most of their proteins from the cytosol because the mitochondrial genome codes for only a small percentage of the polypeptides that reside in the organelle. Recent findings show that the sorting of proteins into the mitochondrial subcompartments and their folding and assembly follow principles already developed in prokaryotes. The components involved may have structural and functional equivalents in bacteria.
\end{abstract}

$M$ ITOCHONDRIA ARE OBLIGATORY CONSTITUENTS OF ALmost every eukaryotic cell and fulfill a variety of metabolic functions. The mitochondrial subcompartments, consisting of the outer membrane, the intermembrane space, the inner membrane, and the matrix, each contain a specific set of in total $\sim 700$ different proteins. Most of these proteins are coded for by nuclear genes and are synthesized in the cytosol. They have to be imported in a continuous process into the growing and dividing organelles (Fig. 1). How do proteins find mitochondria and the correct mitochondrial subcompartment? How do mitochondrial proteins, once translocated across the membranes, attain their functionally active conformation? Our understanding of the general principles of protein translocation across biological membranes has been influenced by studying the mechanisms of mitochondrial protein import. However, mitochondria are organelles of endosymbiotic origin, and prokaryotic rules and mechanisms to handle the proteins imported from the cytosol have been preserved during evolution. We discuss here new insights and ideas resulting from recent progress, focusing mainly on the reactions of intramitochondrial sorting of proteins, and the principles of their folding and assembly.

\section{Cytosolic Precursor Proteins}

The precursors of nuclear-encoded mitochondrial proteins are made on cytosolic polyribosomes and are postrranslationally imported into mitochondria $(1,2)$. Precursors contain targeting sequences of 10 to 70 amino acid residues, which in most cases are localized at the $\mathrm{NH}_{2}$-terminus as cleavable presequences (3). However, target-

The authors are at the Institute of Physiological Chemistry, University of Munich, 8000 Munich 2, Federal Republic of Germany.

* Present address: Molecular Biology Institute, University of California, Los Angeles, CA $90024-1570$. ing information can also reside in regions other than the $\mathrm{NH}_{2}$ terminal portions of precursors $(4,5)$. Mitochondrial targeting signals are rich in positively charged and hydroxylated residues and essentially lack acidic amino acids $(6,7)$. They are necessary and sufficient to direct nonmitochondrial passenger proteins into the mitochondrial matrix (8). In general, the targeting signals share no sequence homology, but many of them have the potential to form amphiphilic $\alpha$ helices or $\beta$ sheets (that is, secondary structural arrangements with the positively charged and the hydrophobic residues being exposed to opposite faces) (9). This amphiphilicity may be important for the initial membrane insertion or the interaction with specific receptor proteins at the mitochondrial surface, or both.

As an essential requirement for the translocation across the mitochondrial membranes, precursor proteins have to maintain a loosely folded conformation after synthesis (10-12). The binding of antibodies, which are tightly folded, to $\mathrm{COOH}$-terminal portions of precursors prevents complete membrane translocation (10). If the tightly folded conformation of dihydrofolate reductase (DHFR),

Fig. 1. Model for the import and sorting of cytochrome $b_{2}$ to the intermembrane space. Precytochrome $b_{2}$ has a bipartite presequence whose $\mathrm{NH}_{2}$-terminal part (zigzag line) is positively charged and contains the information for the targeting into the matrix. The $\mathrm{COOH}$ terminal part of the presequence (hatched box) corresponds to a bacterialtype targeting signal and directs the export to the in-

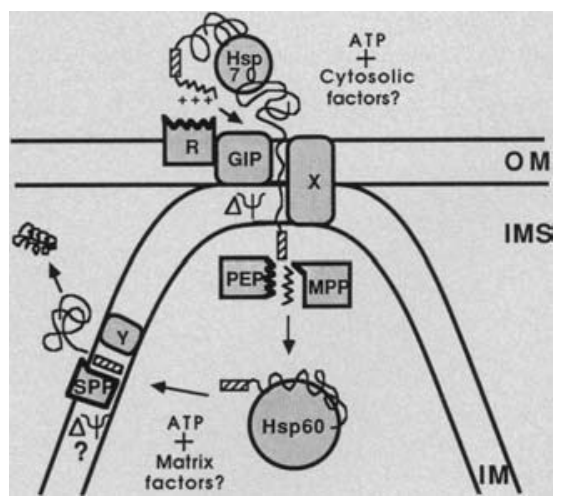
termembrane space (IMS) Cytosolic factors, includ-

ing 70-kD heat-shock proteins (Hsp70), keep the precursor competent for translocation. The precursor binds to a receptor $(R)$ at the surface of the outer membrane $(\mathrm{OM})$. Insertion into $\mathrm{OM}$ is facilitated by the general insertion protein (GIP) in an ATP-dependent reaction. Translocation proceeds via contact sites between $O M$ and the inner membrane (IM) and is mediated by a putative proteinaceous apparatus $(\mathrm{X})$. Insertion into or translocation across IM of the targeting sequence requires the electrical potential $\Delta \Psi$. Matrix targeting sequences are cleaved by the mitochondrial processing peptidase (MPP) in cooperation with the processing-enhancing protein (PEP). Newly imported precursors associate in an unfolded conformation with the heat-shock protein Hsp60. Matrix proteins fold at Hsp60 in an ATP-dependent reaction. In the case of cytochrome $b_{2}, H s p 60$, and maybe additional factors, stabilize the processing intermediate for the export step. Export across IM occurs via a putative machinery (Y). A membraneassociated signal peptidasc (SPP) cleaves the export signal at the outer surface of IM. 
present as a "passenger" in artificial precursors, is stabilized by the folate antagonist methotrexate, the construct is either rendered completely translocation-incompetent or only the sequences fused to the $\mathrm{NH}_{2}$-terminus of DHFR are translocated $(11,12)$. Precursors exist in the cytosol as high molecular weight aggregates (13), and cytosolic cofactors that can stimulate the import reaction in vitro might be part of such aggregates (14). Heat-shock proteins of the Hsp70 family are among the components that prevent misfolding of precursors in the cytosol and thus help to keep their targeting signals exposed (Table 1). Deletion in yeast of three of the four genes coding for constitutively expressed cytosolic $\mathrm{Hsp} 70$ proteins reduced the transport of precursors into mitochondria and into the endoplasmic reticulum (15). Protein import in vitro was stimulated by $\mathrm{Hsp} 70$ proteins $(16,17)$, which are thought to bind to partially unfolded precursors, possibly via hydrophobic interaction (18). This could occur cotranslationally (Fig. 1). Hydrolysis of adenosine triphosphate (ATP) and an N-ethylmaleimide (NEM)-sensitive factor appear to be required for the release of proteins from $\mathrm{Hsp} 70$ (17). Such a factor might be associated with the cytosolic surface of mitochondria.

\section{A General Pathway for Protein Import from the Cytosol}

The first specific step of the import pathway is the binding of precursors to receptor proteins at the surface of the mitochondrial outer membrane $(19,20)$ (Fig. 1). Two outer membrane proteins of Neurospora with molecular masses of $19 \mathrm{kD}$ (MOM19) and $72 \mathrm{kD}$ (MOM72) have been identified as components that participate in the specific recognition of precursors (21) (Table 1). Antibodies recognizing the cytosolic domains of these components inhibit the binding and import of various precursor proteins. MOM19 and MOM72 may represent the mitochondrial targeting-sequence receptors, each being specific for subsets of mitochondrial proteins. They are distributed over the whole surface of the outer membrane but appear to be enriched at contact sites between inner and outer membranes, where translocation takes place. Receptor-bound precursors can probably move laterally toward these membrane contacts.

The entry of precursors into the translocation apparatus is thought to be facilitated by a common component in the outer membrane, the general insertion protein (GIP) (20). This component is relatively well protected from proteases and is probably more deeply embedded in the membrane than the surface receptors. GIP represents an early junction with respect to the intramitochondrial sorting of proteins. Precursors of outer-membrane proteins, such as porin, probably insert directly from GIP into their target membrane (20). Little is known about the signals in outer-membrane proteins required for this step (22). Proteins of the matrix, inner membrane, and intermembrane space are routed from GIP into contact sites for further translocation. GIP has not yet been identified, but good candidates are outer-membrane proteins of $38 \mathrm{kD}$ (MOM38) from Neurospora and $42 \mathrm{kD}$ from yeast $(23,24)$ (Table 1). Antibodies to the latter component inhibited the import reaction in vitro. The precursor of a fusion protein that was arrested at translocation contact sites could be cross-linked to the $42-\mathrm{kD}$ protein $(24,25)$. MOM38 was found to form a complex with the surface receptors MOM19 and MOM72 on extraction from the membrane with detergent (23).

Transport of the majority of authentic precursors from the surface receptor to GIP requires ATP or guanosine triphosphate (GTP) (26). The need for nucleoside triphosphates has been linked to the requirement for the precursor to acquire or maintain a loosely folded

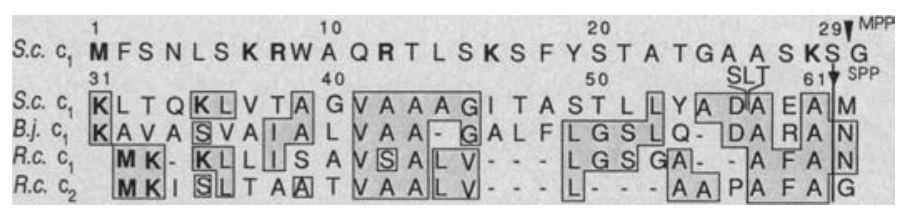

Fig. 2. Comparison of the presequence of yeast cytochrome $c_{1}$ (S.c. $\left.c_{1}\right)(49)$ with bacterial export signals. B.j. $c_{1}$, cytochrome $c_{1}$ of Bradyrhizobium japonicum (64); R.c. $c_{1}$, cytochrome $c_{1}$ of Rhodobacter capsulata; R.c. $c_{2}$, cytochrome $\mathrm{c}_{2}$ of $R$. capsulata (63). The $\mathrm{NH}_{2}$-terminus of the precursor of $B . j$. $c_{1}$ has not been precisely determined (64). Amino acids are shown by the one-letter code (92); positively charged residues shown in bold print. Shaded boxes indicate identical amino acid residues. Dashes represent gaps introduced to maximize sequence alignment. Amino acid residues in the precursor of S.c. $c_{1}$ are numbered starting with the first amino acid of the presequence. MPP, putative cleavage site of the mitochondrial processing peptidase (2, 46). SPP, cleavage sites of the mitochondrial and bacterial signal peptidases.

conformation that allows entry into the translocation machinery (26, 27). It is possible that ATP outside mitochondria is mainly necessary for the release of precursors bound to $\mathrm{Hsp} 70$ or functionally related factors. The import of porin synthesized in a reticulocyte lysate system requires ATP, whereas a purified porin preparation that was artificially unfolded. by acid-base treatment does not (28). The existence of ATP-dependent "unfoldases" has been proposed (29), but it is still uncertain whether ATP is directly required for the unfolding of precursor proteins that can take place at the surface of mitochondria. At least in the case of a DHFR fusion protein, in which the DHFR part folds independently of the mitochondrial presequence and assumes the tightly folded conformation of the native enzyme, we found no detectable ATP requirement for unfolding and subsequent translocation into the matrix (12). According to the present model for heat-shock protein function, Hsp70 would not bind to a correctly folded cytosolic protein such as DHFR.

Transfer from GIP into the inner membrane is dependent on the electrical potential $(\Delta \Psi)$ across the inner membrane $(20,26)$. More specifically, the insertion into or translocation across the inner membrane of the targeting sequences requires an inside negative $\Delta \Psi$, and an electrophoretic effect exerted on the positive charges contained in the targeting sequences has been discussed (30). The precise role of $\Delta \Psi$ is not understood, mainly because the mechanism of protein translocation and the components involved are still unknown. Once the targeting sequence has permeated the inner membrane, the remaining part of the protein follows independently of the $\Delta \Psi(10,12)$.

Protein translocation into mitochondria occurs at sites where outer and inner membranes are in close contact (10). This was suggested by the observation that ribosomes were attached to the outer membrane at membrane contacts (31). Precursor proteins whose complete translocation is blocked by a tight folding of their mature parts can be accumulated in vitro and in vivo as intermediates spanning both membranes at contact sites, reaching far enough into the matrix with their $\mathrm{NH}_{2}$-terminal presequences to be proteolytically processed $(10,12,32)$. Titration experiments revealed that there is a limited number of copies of the translocation machinery $(12,32)$, an average mitochondrion of Neurospora being able to accommodate $\sim 2000$ precursor proteins at contact sites (12). Translocation proceeds through a hydrophilic, possibly proteinaceous, membrane environment (33), but the possibility that protein-lipid interaction may occur during translocation has not been excluded. Most proteins probably enter mitochondria via contact sites $(10,12)$. However, the inner membrane appears, in principle, also competent to translocate precursor proteins in a $\Delta \Psi$-dependent manner outside of contact site regions. Mitoplasts, mitochondria 
whose outer membrane has been largely removed, have an enhanced capacity to import proteins, and import into inner membrane vesicles produced by sonication has been demonstrated $(24,34)$. If we assume that a specific proteinaceous machinery is responsible for protein translocation across the inner membrane, then the respective components may be concentrated in contact site regions. Here, the two membranes would be held in close proximity by unknown structural components, thus bringing the translocation apparatus of the inner membrane in contact with the components of the outer membrane functioning in specific binding and insertion.

\section{Two Components Are Required for Proteolytic Processing}

Once translocated across the mitochondrial membranes, the $\mathrm{NH}_{2}$-terminal presequences of precursors are cleaved by a highly specific metal-dependent processing enzyme in the matrix (35). Presequence cleavage, an essential function (36), is not coupled to membrane translocation but is probably required for proper assembly of the imported proteins. Two structurally related components cooperate in the proteolytic processing, the mitochondrial-processing peptidase (MPP) itself, and the processing-enhancing protein (PEP) (37) (Fig. 1). Both proteins are encoded by nuclear genes and have to be imported from the cytosol as precursors having cleavable presequences themselves $(36,37)$ (Table 1). PEP stimulates the catalytic activity of MPP about 50-fold, MPP being almost inactive in the absence of PEP (37). MPP requires divalent metal cations such as $\mathrm{Mn}^{2+}$ or $\mathrm{Zn}^{2+}$ for activity, but it is unclear whether the enzyme should be classified as a metallopeptidase.

Although MPP cleaves specifically at distinct peptide bonds, analysis of a large number of known cleavage sites revealed no typical consensus signal for processing $(2,38)$. In many cases, however, a basic residue (mostly arginine) is found at position -2 , and often also in position -3 , of the cleavage site. More distant sequences have also been observed to be critical (39). It is possible that the high specificity of cleavage is due to MPP and PEP each recognizing different structural elements of the presequences. How MPP and PEP interact with their substrate and with each other is unknown. It has been suggested that in yeast both components may form a complex of $\sim 100 \mathrm{kD}(40)$, but this has not been observed in Neurospora (37). PEP may bind to the presequences of incoming proteins, thus exposing the cleavage site toward MPP. This binding may occur cotranslocationally. PEP could thereby have a role in translocation of precursors, for example, by releasing the positively charged sequences from a component of the translocation apparatus. For such a function, an $\alpha$-helical segment of about 20 residues having a high net negative charge identified within the sequence of PEP (37) might be important. A deficiency in translocation was

Table 1. Components involved in mitochondrial protein import and assembly.

\begin{tabular}{|c|c|c|}
\hline Component & Function & Reference \\
\hline $\begin{array}{l}\text { Heat-shock proteins }(70 \mathrm{kD}) \text { of the } \mathrm{SSA} \text { subgroup } \\
\text { (Hsp70): soluble }\end{array}$ & $\begin{array}{l}\text { Cytosol } \\
\text { Stabilization of precursors in a loosely folded, translocation- } \\
\text { competent conformation }\end{array}$ & $(15,16,18)$ \\
\hline $\begin{array}{l}\text { NEM-sensitive factors (not identified): possibly bound } \\
\text { to outer-membrane surface }\end{array}$ & $\begin{array}{l}\text { Cooperation with Hsp70; proposed to be required for release } \\
\text { of Hsp70-bound precursors }\end{array}$ & $(17)$ \\
\hline $\begin{array}{l}\text { MOM19 of Neurospora crassa }(19 \mathrm{kD}) \text { : exposed to } \\
\text { cytosol; partially alkali extractable }\end{array}$ & $\begin{array}{l}\text { Outer membrane } \\
\text { Binding protein for precursor of porin and for precursor proteins } \\
\text { with } \mathrm{NH}_{2} \text {-terminal targeting sequences }\end{array}$ & $(21)$ \\
\hline $\begin{array}{l}\text { MOM72 of } N \text {. crassa }(72 \mathrm{kD}) \text { : exposed to cytosol; } \\
\text { resistant to alkaline extraction }\end{array}$ & $\begin{array}{l}\text { Binding protein used by the precursor of the ADP-ATP-carrier } \\
\text { and possibly also related proteins }\end{array}$ & $(21,23)$ \\
\hline $\begin{array}{l}\text { General insertion protein (GIP) (not identified): possible } \\
\text { candidates include MOM38 of } N \text {. crassa }(38 \mathrm{kD} \text { ) and } \\
42-\mathrm{kD} \text { protein of Saccharomyces cerevisiae }\end{array}$ & $\begin{array}{l}\text { Facilitation of insertion of precursors into outer membrane; accepts } \\
\text { precursors from different surface receptors; transfer to } \\
\text { GIP requires ATP or GTP (possibly for release from Hsp70) }\end{array}$ & $(23,24,25)$ \\
\hline $\begin{array}{l}\text { Cytochrome c-heme lyase: } 38 \mathrm{kD} \text { in } N \text {. crassa, } 32 \mathrm{kD} \\
\text { in } S \text {. cerevisiae; peripheral membrane protein at } \\
\text { inner aspect of outer membrane or outer aspect of } \\
\text { inner membrane at contact sites }\end{array}$ & $\begin{array}{l}\text { Intermembrane space } \\
\text { Covalent attachment of heme to apocytochrome c; role in } \\
\text { specific binding and membrane translocation of cytochrome c }\end{array}$ & $(81,83)$ \\
\hline
\end{tabular}

Signal peptidases (not identified): probably exposed to the intermembrane space; possible evolutionary relation to bacterial signal peptidases

Mitochondrial processing peptidase (MPP): soluble; $57 \mathrm{kD}$ in $N$. crassa, $52 \mathrm{kD}$ in $S$. cerevisiae (product of $M A S 2 / M I F 2$ gene)

Processing-enhancing protein (PEP). N. crassa: $52 \mathrm{kD}$; $70 \%$ peripherally attached to inner membrane, $30 \%$ soluble; identical with core I protein of complex III. S. cerevisiae: $48 \mathrm{kD}$; soluble; product of MAS1 gene; $24 \%$ identity with yeast core 1 protein

Hsp60: soluble 14-subunit complex of $\sim 800 \mathrm{kD}$; monomer $58 \mathrm{kD}$ in $N$. crassa, $60 \mathrm{kD}$ in $S$. cerevisiae (product of MIF4 gene); $\sim 50 \%$ identity with $E$. coli Gro EL; constitutively expressed; two- to three-fold induction upon heat-shock

SSCl-protein of $S$. cerevisiae (member of Hsp70 family): $\mathbf{5 8 \%}$ identity with $E$. coli DNAk

Inner membrane

Second proteolytic processing of intermembrane space precursors with bipartite presequences; cleavage of precursor of cytochrome oxidase subunit II

\section{Matrix}

Cleavage of $\mathrm{NH}_{2}$-terminal presequences of imported precursors; dependent on divalent metal cations; inhibited by chelators in situ; isolated enzyme inhibited by NEM

Cooperation in presequence cleavage with MPP; stimulation of MPP activity; role in membrane-translocation of precursors; probably interacts cotranslocationally with $\mathrm{NH}_{2}$ terminal presequences

ATP-dependent folding of imported proteins; stabilization of translocation-competent conformation of reexported proteins; "chaperonin" function in oligomeric protein assembly; possible repair function for misfolded proteins

Essential for growth of yeast; function unknown 
demonstrated in mitochondria of the temperature-sensitive yeast mutant mas1/mif1 (mas, for mitochondrial assembly; mif, for mitochondrial import function), which is defective in the gene encoding PEP $(41,42)$. Inhibition of MPP, however, does not reduce the efficiency of import (36).

Although functionally different, MPP and PEP are structurally related, having $26 \%$ amino acid sequence identity $(36,37)$. MPP and PEP belong to a larger protein family, which also contains the core proteins 1 and 2 (subunits I and II) of the cytochrome $b c_{1}$ complex (complex III) of the respiratory chain (43). The core proteins seem to function in the assembly of complex III $(43,44)$. The evolutionary background of their relation to the processing enzyme is unknown. PEP is identical with core protein 1 in Neurospora and is encoded by the same gene (43). Core protein 1 present in the isolated $b c_{1}$ complex has processing-enhancing activity at least in vitro. In yeast, core protein 1 and PEP are encoded by different genes, but their amino acid sequences are $24 \%$ identical (43). This situation probably reflects the ability of yeast to repress respiratory chain complexes on fermenting growth media but to maintain the machinery for protein import in the promitochondria formed under these conditions.

\section{Protein Export to the Intermembrane Space}

Proteins residing in the matrix reach their target compartment by translocation across the two membranes at contact sites. What additional reactions are required for proteins of the inner membrane or the intermembrane space to arrive at their correct location?

For several proteins of the intermembrane space, complete translocation at contact sites into the matrix could be demonstrated (45, 46). Originally, a different sorting pathway based on a stop-transfer mechanism across the inner membrane had been proposed, at least for cytochrome $c_{1}$ (47). Proteins like cytochrome $b_{2}$, a soluble component of the intermembrane space of yeast mitochondria, and cytochrome $c_{1}$ of the $b c_{1}$ complex, which is largely exposed to the intermembrane space, are synthesized as cytosolic precursors with long, complex presequences $(48,49)$. These presequences have a bipartite structure and are cleaved in two steps by different processing peptidases $(46,47,50)$. Their $\mathrm{NH}_{2}$-terminal parts exhibit the typical features of the positively charged mitochondrial targeting sequences (Fig. 2). Cleavage by the processing enzyme MPP-PEP in the matrix removes these $\mathrm{NH}_{2}$-terminal segments of the presequences resulting in the formation of intermediate-sized species. The remaining $\mathrm{COOH}$-terminal parts of the presequences contain essentially uninterrupted hydrophobic stretches of $\sim 20$ residues that are preceded by one to four basic residues, a motif reminiscent of the leader sequences that target the export of proteins across the plasma membrane in bacteria (51). Also in the case of the intermembrane space proteins, the COOH-terminal segments of the presequences direct the export of the intermediate-sized species from the matrix back across the inner membrane (46). This was shown with the use of fusion proteins between the complete presequences of cytochromes $b_{2}$ or $c_{1}$ and passenger proteins such as DHFR or cytochrome $c(12,52)$. Both the authentic proteins and the artificial precursors could be detected as soluble species in the matrix if the import reaction was carried out at low temperature $\left(10^{\circ} \mathrm{C}\right)$ or in the presence of metal chelators to inhibit the first processing step. Raising the temperature to $25^{\circ} \mathrm{C}$ and reactivation of MPP by adding $\mathrm{Mn}^{2+}$ ions initiated the retranslocation of the processing intermediates across the inner membrane followed by proteolytic processing to the mature size (46) (Fig. 1). As a further analogy to bacterial protein export, this second processing event is catalyzed by an as yet unidentified membrane-associated processing peptidase at the outer surface of the inner membrane $(46,50)$. A conditional yeast mutant affecting a single nuclear gene has been described that is defective in the second processing step of cytochrome $b_{2}$ and in the processing of the precursor of subunit II of cytochrome oxidase (53). The latter is an inner membrane protein encoded by the mitochondrial genome that exposes large parts of its sequence to the intermembrane space (44).

Little is known about the molecular details of mitochondrial protein export. For cytochrome $b_{2}$, retranslocation from the matrix appears to be independent of the $\Delta \Psi$ across the inner membrane; in contrast to cytochrome $c_{1}$, where such a dependence was suggested (46). It is possible, however, that in the case of cytochrome $c_{1}, \Delta \Psi$ is required in connection with the covalent attachment of heme to the intermediate-sized protein by cytochrome $c_{1}$-heme lyase. Heme addition appears to be a prerequisite for the second proteolytic processing step of cytochrome $c_{1}(52,54)$. Recent findings indicate an ATP requirement for mitochondrial protein export. ATP is needed for the release of the imported proteins from the heat-shock protein $\mathrm{Hsp} 60$ in the matrix $(55,56)$. This component is structurally and functionally equivalent to the GroEL protein of Escherichia coli (57) (Table 1) and is essential for the folding and assembly of mitochondrial proteins (see below). Its role in mitochondrial protein export is probably similar to the function of the GroEL protein, which, among other factors, stabilizes precursors for translocation across the bacterial plasma membrane (58).

It is not known whether the machinery for mitochondrial protein export is distributed evenly over the inner membrane or whether it is concentrated in specialized inner membrane regions such as the inner boundary membrane. The export step is at least possible in very close proximity to the translocation contact sites used for protein import. Complete translocation into the matrix of a fusion protein consisting of the first 330 to 560 residues of the cytochrome $b_{2}$ precursor fused to DHFR was prevented in the presence of methotrexate (59). Under these conditions, the complete DHFR portion remained outside the mitochondria, whereas the cytochrome $b_{2}$ part of the construct was retranslocated across the inner membrane and was cleaved at the second processing site. This reaction appears to be dependent on the function of the matrixlocalized Hsp60.

\section{The Principle of Conservative Intramitochondrial Sorting}

As generally accepted, mitochondria, and also chloroplasts, have evolved from prokaryotic ancestors that were introduced into an ancestral eukaryotic host cell by an endosymbiotic event (60). Although this occurred probably more than a billion years ago, a great number of structural and functional similarities between mitochondria and prokaryotes support the idea of the endosymbiotic origin of the former. Prokaryotic principles of membrane assembly and transport have also been conserved during the evolution of mitochondria $(45,46)$.

This can be exemplified by comparing the assembly pathways of components of the mitochondrial and bacterial cytochrome $b c_{1}$ complexes. Both Paracoccus and Rhodobacter are probably close relatives to the endosymbiotic ancestor of mitochondria and contain in their plasma membranes or photosynthetic membranes, respectively, $a b c_{1}$ complex that is highly homologous to that in mitochondria (61). For example, the cytochrome $c_{1}$ of Rhodobacter capsulata is synthesized in the bacterial cytosol with a typical bacterial export signal that shows considerable similarity to the second part of the presequence of yeast cytochrome $c_{1}(49,62)$ (Fig. 2). This is also true for the leader sequences of $R$. capsulata cytochrome $c_{2}(63)$, the 
equivalent to mitochondrial cytochrome $c$, and of cytochrome $c_{1}$ of Bradyrhizobium japonicum (64). Bradyrhizobium is a true endosymbiotic bacterium that lives in the root nodules of soy bean. In bacteria, the precursor of cytochrome $c_{1}$ is translocated to the periplasmic side of the plasma membrane and is proteolytically cleaved. The "conservative sorting hypothesis" proposed that this pathway has been conserved in mitochondria with respect to the export of the intermediate-sized species of cytochromes $c_{1}$ and $b_{2}$, and probably other intermembrane space proteins, from the matrix across the inner membrane $(45,46)$ (Fig. 3). The participation of the evolutionarily conserved $\mathrm{Hsp} 60$ and GroEL in this pathway supports this hypothesis $(55,56)$. Other components functioning in bacterial protein export such as the SecA, SecY, and SecB proteins, trigger factor, and leader peptidase may also have mitochondrial homologs (65).

In principle, the same considerations apply to protein sorting within chloroplasts. For example, cytochrome $f$ in the thylakoid membrane, the equivalent of mitochondrial cytochrome $c_{1}$, is made in the chloroplast stoma with a bacterial-type presequence that directs its translocation across the thylakoid membrane (66) (Fig. 3). Plastocyanin, the functional counterpart of cytochrome $c$, is synthesized in the cytosol as a precursor carrying a bipartite presequence that directs its transport first into the chloroplast stroma and then, after the first cleavage by the stromal processing enzyme, across the thylakoid membrane (67). The thylakoid peptidase responsible for the processing of cytochrome $f$ and for the second cleavage of plastocyanin is also able to remove the leader sequences of authentic bacterial precursors $(68)$.

The Rieske Fe-S protein, a peripheral component of the $b c_{1}$ complex at the outer surface of the mitochondrial inner membrane, also reaches its functional location on an import route via the matrix $(45,55,56)$. Its presequence is cleaved in two steps, but both processing events take place in the matrix, and there is no hydrophobic segment in the prepeptide (69). Information for retranslocation across the inner membrane must therefore reside in the mature protein part. Likewise, an Fe-S protein in the bacterium Desulfovibrio vulgaris is translocared to the periplasmic space without a cleavable hydrophobic signal (70). Also the $F_{0}$-adenosine triphosphatase $\left(F_{0^{-}}\right.$ ATPase) subunit 9 of Neurospora, a typical integral component of the
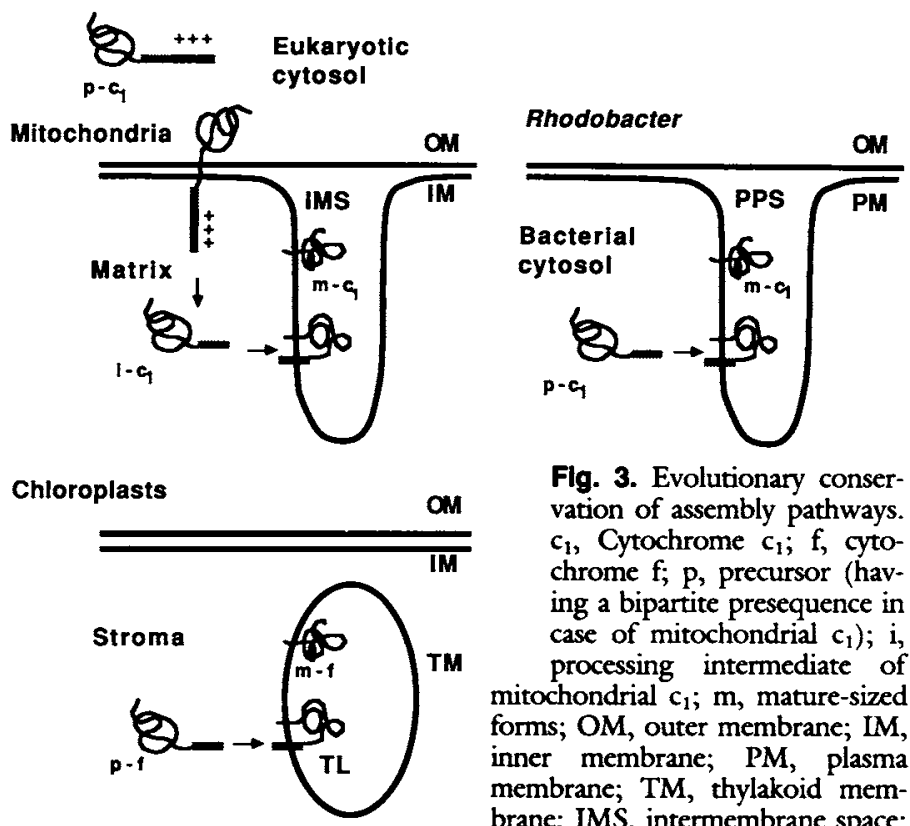

Flg. 3. Evolutionary conservation of assembly pathways. $c_{1}$, Cytochrome $c_{1} ; f$, cytochrome $\mathrm{f} ; \mathrm{p}$, precursor (having a bipartite presequence in case of mitochondrial $c_{1}$ ); $i$, processing intermediate of mitochondrial $c_{1} ; m$, mature-sized forms; OM, outer membrane; IM, inner membrane; PM, plasma membrane; TM, thylakoid membrane; IMS, intermembrane space; PPS, periplasmic space; TL, thylakoid lumen. inner membrane, integrates into the inner membrane after complete translocation into the matrix (71). This process seems to correspond to the insertion of the ATPase subunit $c$ into the plasma membrane in bacteria. Imported subunit 9 has to interact transiently with the Hsp60 in the matrix, which has an essential function in the sorting of most proteins of the inner membrane and intermembrane space $(55,56,71)$ (Fig. 4). Subunit 9 is coded for by a nuclear gene only in Neurospora and in higher eukaryotes. In yeast and in plants, the protein is encoded by the mitochondrial genome and made without a presequence $(6,72)$.

\section{Evolutionary Considerations}

Gene transfer from the prokaryotic invader to the nucleus of the proto-eukaryotic host, having occurred at some time after the endosymbiotic event, is usually held responsible for the fact that most mitochondrial proteins are coded for by the nucleus $(60)$. To remain in their ancestral compartment, the proteins then had to acquire the positively charged targeting sequences in addition to already present prokaryotic transport signals. Accidental recombination events with nuclear DNA might have been sufficient to serve this purpose as segments of DNA coding for potential mitochondrial targeting sequences appear to be present in every genome. When random fragments of bacterial or eukaryotic genomic DNA were fused to the nucleotide sequence coding for the mature part of cytochrome oxidase IV, more than $10 \%$ of the sequences were able to direct the transport of the resulting fusion protein into mitochondria with sufficient efficiency to rescue a defect in the endogenous cytochrome oxidase subunit IV (73).

In parallel to the evolution of targeting signals, translocation contact sites must have been developed by mitochondria to accomplish the import of the cytosolic precursor proteins. How this happened is difficult to envision. If we assume that the outer mitochondrial membrane corresponds to the outer membrane of the prokaryotic ancestor, instead of being derived from the endomembrane system of the host cell, contact sites might have evolved from preexisting "adhesion sites" of the endosymbiont (60). The prokaryotic ancestor might even have possessed a "primitive" apparatus for protein import. For example, some colicins, bacteriocidal exotoxins, are transported from outside into the $E$. coli plasma membrane in a reaction that is dependent on a receptor in the outer membrane and on the $\Delta \Psi$ (negative inside) across the plasma (inner) membrane. This may occur at sites of adhesion (74).

With the use of recombinant DNA methodology, the transfer of genes from the mitochondrial genome to the nucleus and the import of the now cytosolically expressed proteins back into the organelle can be reproduced $(75,76)$. For example, the mitochondrial gene coding for the precursor of cytochrome oxidase subunit II (preCoxII) was altered by site-directed mutagenesis to allow synthesis of the protein in a eukaryotic reticulocyte lysate. The presequence of Neurospora $\mathrm{F}_{0}$-ATPase subunit 9 joined to the $\mathrm{NH}_{2}$-terminus of preCoxII was able to direct the import of the construct into isolated mitochondria (75). Cleavage by MPP-PEP in the matrix resulted in the formation of preCoxII, which was subsequently retranslocated across the inner membrane and processed to the mature-sized protein. It is not known why the mitochondrial genome and the apparatus for its expression are maintained. It was proposed that the mitochondrial gene products were too hydrophobic to become translocated across the mitochondrial membranes or that mistargeting to the endoplasmic reticulum might occur (77). It seems now rather unlikely that this is the sole reason why mitochondria synthesize a small subset of mostly respiratory chain components and a ribosomal protein. 


\section{Nonconservative Sorting of Proteins}

A few proteins are known whose assembly pathways do not conform to the rules of conservative sorting. For the time being, they can be treated as exceptions, but it is possible that a number of nuclear-coding proteins use other ways to reach their submitochondrial compartments. It is useful to distinguish here between proteins that probably have no structurally related counterparts in prokaryotes and others that do have such equivalents. To the first group belongs the adenosine diphosphate (ADP)- and ATP-carrier (AAC) of the inner membrane and probably also the other structurally related substrate-carrier proteins of mitochondria, including the uncoupling protein of brown adipose tissue and the phosphatecarrier (78). The import pathway of the AAC has been studied extensively $(20,26)$. Notably, the cytosolic precursor is made without a cleavable presequence (4). Targeting information appears to reside in triplicate internal segments (79). The AAC is the only protein known to be recognized by the surface receptor MOM72; all precursors tested so far having typical presequences interact with MOM19 (21). Nevertheless, the AAC uses GIP for entry into the outer membrane and is subsequently transported into contact sites $(20,26)$. Here, the AAC appears to deviate from the general import pathway by laterally diffusing into the inner membrane. The import of the AAC is independent of any interaction with Hsp60 (71). The signals and mechanisms that prevent translocation into the matrix and trigger integration into the inner membrane are unknown. In case of the uncoupling protein, which appears to follow an AAC-like import pathway, attachment of a positively charged presequence to the $\mathrm{NH}_{2}$-terminus of the protein is able to override these mechanisms, leading to translocation into the matrix (79).

Cytochrome $\mathrm{c}$ is a component whose origin reaches back beyond the development of eukaryotic cells (80). Its prokaryotic equivalents are made with bacterial leader sequences that direct the transport of the precursor across the plasma membrane to the periplasmic space (63) (Fig. 2). Cytochrome $\mathrm{c}$ does not follow a reexport pathway; it reaches the intermembrane space by crossing only the outer membrane, independently of the $\Delta \Psi$ across the inner membrane $(81,82)$. The precursor, apocytochrome $c$, is made without a cleavable

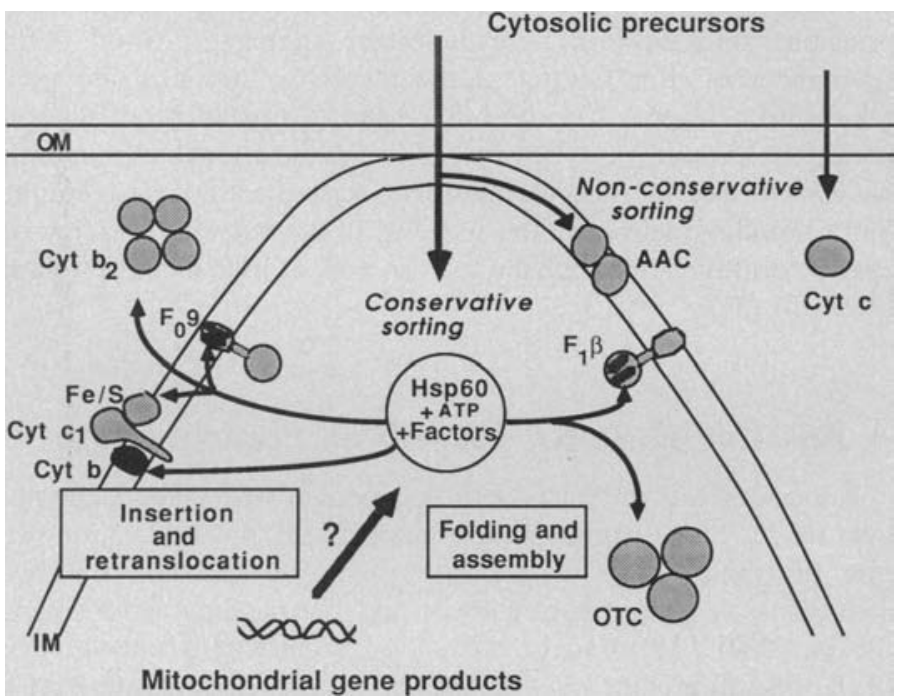

Fig. 4. Model for the role of $\mathrm{Hsp} 60$ in intramitochondrial sorting and assembly. Cyt c, cytochrome $c ; c y t b_{2}$, cytochrome $b_{2} ;$ cyt $c_{1}$, cytochrome $c_{1}$; $\mathrm{Fe}-\mathrm{S}$, Rieske $\mathrm{Fe}-\mathrm{S}$ protein; $\mathrm{F}_{0} 9$, subunit 9 of $\mathrm{F}_{0}$-ATPase; cyt b, cytochrome b; AAC, ADP-ATP-carrier; $F, \beta, \beta$ subunit of $F_{1}$-ATPase; OTC, ornithine transcarbamylase. Proteins encoded within mitochondria $\left(C y t b, F_{0} 9\right)$ are shown in black. The interaction of $\mathrm{Hsp} 60$ with these polypeptides has not been demonstrated, so far. presequence (5), and a receptor protein at the surface of mitochondria seems not to be required for import. Apocytochrome $\mathrm{c}$ tends to insert spontaneously into lipid membranes (82), and this may have allowed the evolution of its exceptional import pathway. Specific targeting as well as completion of translocation across the outer membrane are probably mediated by the interaction with cytochrome $\mathrm{c}-$ heme lyase at the inner face of the outer membrane and by covalent attachment of heme (81-83) (Table 1). Apocytochrome $c$ also maintains the ability to insert into the outer membrane when a positively charged presequence is fused to its $\mathrm{NH}_{2}$-terminus. A fusion protein between apocytochrome $\mathrm{c}$ and the bipartite presequence of cytochrome $c_{1}$ was efficiently forced onto a conserved sorting pathway via the matrix (82).

Other proteins of the intermembrane space having similar properties may exist. Recent data suggest that the precursor of cytochrome c peroxidase, also a heme protein of the intermembrane space, can reach its target compartment by directly crossing the outer membrane (84). This is surprising as cytochrome $\mathrm{c}$ peroxidase contains a typical bipartite presequence like cytochrome $b_{2}$ or cytochrome $c_{1}$ (7), suggesting an import route via the matrix. Cytochrome c peroxidase might represent an interesting intermediate stage of the evolution of a cytochrome c-like import pathway.

\section{Catalyzed Folding of Mitochondrial Proteins}

The selection of a yeast mutant defective in the gene encoding the matrix-localized $\mathrm{Hsp} 60$ added new aspects to our understanding of protein folding and assembly in vivo (55). Hsp60 is highly homologous to the GroEL protein of $E$. coli and to the ribulose bisphosphate carboxylase (Rubisco)-binding protein of chloroplasts, both of which have been classified as members of a subgroup of "molecular chaperones" termed "chaperonins" (57) (Table 1). Like the other chaperonins, Hsp60 forms an oligomeric complex consisting of two stacked rings of seven $60-\mathrm{kD}$ subunits each. As originally defined, chaperonins have assisting functions in protein assembly reactions, such as the formation of phage particles in $E$. coli or the assembly of small and large subunits of Rubisco in chloroplasts. Chaperonins do not occur as part of the finally assembled protein complexes (57).

The consequences of the loss of $\mathrm{Hsp} 60$ function were analyzed in the temperature-sensitive yeast mutant mif4 (55) (Fig. 4). Among others, the precursors of the $\beta$ subunit of the $F_{1}$-ATPase, the matrix enzyme ornithine transcarbamylase, and $\mathrm{Hsp} 60$ itself were imported and proteolytically processed at the restrictive temperature, but failed to assemble into their respective oligomeric complexes. Imported proteins were detected as amorphous aggregates associated with the mitochondrial membrane fraction. Proteins of the intermembrane space and the inner membrane were also affected. For example, export of cytochrome $b_{2}$ or of the Rieske Fe-S protein was defective and the proteins accumulated as incompletely processed intermediates in the matrix (55). A similar observation was made with the precursor of $\mathrm{F}_{0}$-ATPase subunit 9 (71). Interaction with Hsp60 apparently keeps imported proteins competent for insertion into or retranslocation across the inner membrane. Such a function in protein export was suggested for the GroEL protein in E. coli (58).

How does Hsp60 function and how do imported precursor proteins interact with Hsp60? With the use of fusion proteins between variable lengths of the $\mathrm{NH}_{2}$-terminal sequence of the precursor of cytochrome $b_{2}$ and DHFR, as few as 46 residues were sufficient to span inner and outer membranes at contact sites if the folded DHFR stabilized by methotrexate remained outside mitochondria (12). This indicates that precursor proteins traverse the 
mitochondrial membranes in a rather extended conformation, which may be comparable to that of a nascent polypeptide chain. Analyzing the import of a similar fusion protein revealed that it is these "unfolded," newly imported polypeptides that interact with Hsp60 (56). Unfolding the precursor by urea treatment before import resulted in rapid translocation into mitochondria. This experimental system allowed a kinetic separation between membrane-translocation and refolding of the imported protein. A system to study protein folding in vivo was thus developed that was accessible to biochemical manipulation (56). Membrane translocation was complete within less than $1 \mathrm{~min}$. Proteolytic processing in the matrix resulted in the formation of the mature-sized fusion protein, which was almost identical to DHFR. AT $25^{\circ} \mathrm{C}$, refolding of DHFR occurred with a half-time of about $3 \mathrm{~min}$, considerably more slowly than translocation of the urea-denatured precursor. Folding was ATP-dependent: in ATP-depleted mitochondria, DHFR accumulated in a highly protease-sensitive conformation at the surface of the Hsp60 scaffold. An antibody to SDS-denatured DHFR efficiently recognized the Hsp60-associated protein but not the folded monomeric form. The stoichiometry of the complex formed has yet to be determined. ATP hydrolysis was required to cause folding and release of DHFR from Hsp60.

The mechanism of action of $\mathrm{Hsp} 60$ has been further analyzed. When the complex between the imported protein and Hsp60 was partially purified, addition of ATP caused folding of DHFR into a more compact conformation but not release from $\mathrm{Hsp} 60$ (56). An as yet unidentified factor required for the release reaction was probably lost during purification. The molecular details of the reaction by which $\mathrm{Hsp} 60$ mediates protein folding remain unclear. As a working hypothesis, Hsp60, which has ATPase activity, could undergo conformational changes upon ATP hydrolysis. This might somewhat loosen the interaction with the bound polypeptide, thus enabling its controlled, domain-wise folding at the surface of Hsp60. This reaction appears to be NEM-sensitive, as folding of DHFR was blocked in NEM-treated mitochondria (56). Nevertheless, the imported polypeptides bound transiently to Hsp60. They were released in an ATP-dependent reaction, but failed to fold correctly and formed insoluble misfolded aggregates.

It would appear that $\mathrm{Hsp} 60$ must be able to recognize structural motifs present in every unfolded or loosely folded polypeptide chain. The type of interaction and the nature of the physical forces involved are unclear. For Hsp70 proteins, it was proposed that interaction with hydrophobic residues exposed by incompletely folded or misfolded proteins might be important (18). This is in contrast to results stressing the importance of charged polypeptide regions. Short hydrophilic peptides of between 8 and 25 residues were shown to mimic polypeptide chain substrates in terms of their ATP-dependent interaction with members of the Hsp70 protein family (85).

\section{Reconsidering Protein Folding in Vivo}

Why does the folding of proteins in mitochondria require "catalysis" by a proteinaceous machinery? This seems a paradox in light of the observation that rapid spontaneous refolding of proteins is possible after denaturation in vitro (86), and it was concluded that polypeptide chains spontaneously fold during synthesis in vivo in an essentially similar way. However, more complex or multimeric enzymes cannot reassemble in vitro or do so exceedingly slowly (86). Additional mechanisms of protein folding are probably operative in intact cells that help to realize the information for the folded structure residing in the amino acid sequence of the polypeptide chain.
DHFR is one example of a monomeric protein that undergoes refolding in vitro within seconds (87), and yet, DHFR takes minutes to fold inside mitochondria (56). Perhaps the most significant difference between protein folding in vitro and in vivo is that only in vitro are all parts of a protein equally available for folding under the same conditions. Within the cell this is not the case when a protein emerges from the ribosome at a speed of a few amino acids per second or when it appears at the trans side of a membrane. Especially for multidomain proteins, it seems likely that incompletely synthesized or translocated polypeptide chains would rather spontaneously misfold, because folding would be restricted to only parts of the protein, exclusively starting from the $\mathrm{NH}_{2}$-terminus. $\mathrm{NH}_{2}$ - or $\mathrm{COOH}$-terminal deletions of a few amino acids can also cause incorrect folding in vitro (86). Hsp60 and similar components may prevent folding until the complete polypeptide is available. Synthesis of an average protein of 50 to $60 \mathrm{kD}$ takes several minutes in a eukaryotic cell (88), a time which corresponds well to the halftime observed for the Hsp60-mediated folding of DHFR (56). To have such "antifolding" activity, $\mathrm{Hsp} 60$ would require a high affinity for an unfolded state of its protein substrates. In fact, in the absence of ATP, DHFR remained stably bound to Hsp60 in a very proteasesensitive conformation (56). This would also explain the function of Hsp60 and GroEL in keeping proteins loosely folded long enough to allow membrane translocation. So far, DHFR is the only protein for which at least partial ATP-dependent folding at the surface of Hsp60 was observed. Nevertheless, this suggests that Hsp60 can do more than just prevent premature folding. Simply to release a completely synthesized or translocated polypeptide as an unfolded chain (a situation comparable to in vitro folding) is probably not sufficient. It may be important to consider here that physiological folding takes place in a highly concentrated protein solution. Although slower than spontaneous folding in vitro, folding at the surface of Hsp60 would still be catalyzed. With respect to the formation of the correctly folded product, $\mathrm{Hsp} 60$-mediated folding is far more efficient than spontancous folding in vivo, which results in misfolded proteins (56). It remains to be seen whether Hsp70 proteins in the cytosol or within subcellular organelles $(89)$, have a function in folding of proteins similar to that of Hsp60.

How are the functions of chaperonins in oligomeric protein assembly $(55,57)$ related to the function in protein folding $(56)$ ? In principle, formation of supramolecular aggregates could occur spontaneously after folding of the respective subunits and their release from $\mathrm{Hsp60}$. On the other hand, complementary surfaces critical for assembly may be exposed in a programmed fashion only, while the respective subunits are still associated with the chaperonin. Simple model systems like the assembly of the mitochondrial matrix enzyme ornithine transcarbamylase can now be used to address these problems (55).

\section{A Possible Role for Hsp60 in Translocation}

Precursors could interact cotranslocationally with $\mathrm{Hsp} 60$, and this may render further translocation energetically favorable. Completion of translocation of a fusion precursor spanning the two membranes at contact sites with its $\mathrm{NH}_{2}$-terminal part, but having the folded DHFR still in the cytosol, is less efficient in mitochondria of the Hsp60 mutant (55). In wild-type organelles, this process is strictly temperature-dependent and takes place in the absence of both ATP and the $\Delta \Psi(12,56)$. The energy required for unfolding of a protein is in the range of only 5 to $15 \mathrm{kcal} / \mathrm{mol}$. One may speculate that by interacting with the extended $\mathrm{NH}_{2}$-terminus of a precursor reaching into the matrix, Hsp60 could trigger the complete unfolding of a protein, thus "pulling" it across the membranes. 
Import should cease once Hsp60 is saturated and would only resume after ATP-mediated clearing of proteins from Hsp60. Import in vitro was shown to be dependent on the presence of ATP in the matrix (90). The proposed role for $\mathrm{Hsp} 60$ may be applicable to membrane transport of proteins in a more general way. In fact, the immunoglobulin heavy chain-binding protein BiP, an Hsp70 protein located at the luminal surface of the endoplasmic reticulum, might have a function in protein translocation. In the yeast mutant kar2, which is affected in the gene coding for BiP, precursors of secretory proteins accumulate in the cytosol (91).

\section{Concluding Remarks}

The dissecting of the import pathway of proteins into mitochondria has revealed unexpected mechanisms of intracellular protein sorting and assembly. Their accessibility to the methods of both classical biochemistry and molecular genetics makes mitochondria a suitable model system for understanding the complete sequence of reactions required for a cytosolic nascent polypeptide chain to reach its functionally active conformation in the correct subcellular compartment. Recent findings are giving us a clue as to how proteins may fold in vivo. This is a challenge to reconstitute these processes using the isolated components. But clearly, our knowledge is still very limited. A number of important questions have yet to be answered. The molecular mechanism of protein translocation across membranes itself and the components involved, especially those residing in the membrane, are still a mystery. How are the complex processes of protein assembly regulated, particularly in the case of respiratory chain complexes, which contain subunits coded for by the nuclear and the mitochondrial genome? Mitochondria may be considered as miniature cells inside cells. Quite likely, they have more surprises in store.

\section{REFERENCES AND NOTES}

1. G. Attardi and G. Schatz, Annu. Rev. Cell Biol. 4, 289 (1988); N. Pfanner, F.-U. Hartl, W. Neupert, Eur. J. Biochem. 175, 205 (1988).

2. F.-U. Hartl, N. Pfanner, D. W. Nicholson, W. Neupert, Biochim. Biophys. Acta 998, 1 (1989).

3. M. A. Harmey and W. Neupert, FEBS Lett. 108, 385 (1979); M.-L. Maccecchini, Y. Rudin, G. Blobel, G. Schatz, Proc. Natl. Acad. Sci. U.S. A. 76, 343 (1979); R Michel, E. Wachter, W. Sebald, FEBS Lett. 101, 373 (1979).

4. R. Zimmermann, U. Paluch, M. Sprinzl, W. Neupert, Eur. J. Biochem. 99, 247 (1979).

5. R. Zimmermann, U. Paluch, W. Neupert, FEBS Lett. 108, 141 (1979).

6. A. Viebrock, A. Perz, W. Sebald, EMBO J. 1, 565 (1982).

7. J. Kaput, S. Goltz, G. Blobel, J. Biol. Chem. 257, 15054 (1982).

8. E. C. Hurt, B. Pesold-Hurt, G. Schatz, FEBS Lett. 178, 306 (1984); A. L Horwich, F. Kalousek, I. Mellman, L. E. Rosenberg, EMBO J. 4, 1129 (1985).

9. D. Roise et al., EMBO J. 7, 649 (1988); G. von Heijne, ibid. 5, 1335 (1986).

10. M. Schleyer and W. Neupert, Cell 43,339 (1985); M. Schwaiger, V. Herzog, W. Neupert, J. Cell Biol. 105, 235 (1987).

11. M. Eilers and G. Schat, Nature 322, 228 (1986); D. Vestweber and G. Schatz, EMBO J. 7, 1147 (1988).

12. J. Rassow et al., J. Cell Biol. 109, 1412 (1989); J. Rassow, J. Ostermann, B. Guiard, F.-U. Hartl, W. Neupert, unpublished data.

13. R. Zimmermann and W. Neupert, Eur. J. Biochem. 109, 217 (1980); W.-J. Chen and M. G. Douglas, J. Biol. Chem. 263, 4997 (1988)

14. C. Argan and G. C. Shore, Biochim. Biophys. Acta 131, 289 (1985); H. Ono and S. Tuboi, J. Biol. Chem. 263, 3188 (1988).

15. R. J. Deshaies, B. D. Koch, M. Werner-Washburne, E. A. Craig, R. Schekman, Nature 332, 800 (1988).

16. W. J. Chirico, M. G. Waters, G. Blobel, ibid., p. 805; R. Zimmermann, M. Sagstetter, M. J. Lewis, H. R. B. Pelham, EMBO J. 7, 2875 (1988)

17. H. Murakami, D. Pain, G. Blobel, J. Cell Biol. 107, 2051 (1988); S. K. Randall and G. C. Shore, FEBS Lett. 250, 561 (1989).

18. H. R. B. Pelham, Cell 46, 959 (1986); Nature 332, 776 (1988)

19. H. Riezman, R. Hay, C. Witte, N. Nelson, G. Scharz, EMBO J. 2, 1113 (1983); C. Zwizinski, M. Schleyer, W. Neupert, J. Biol. Chem. 258, 4071 (1983); R. Pfaller, H. Freitag, M. A. Harmey, R. Benz, W. Neupert, ibid. 260, 8188 (1985); R. Pfaller and W. Neupert, EMBO J. 6, 2635 (1987).

20. N. Pfanner and W. Neupert, J. Biol. Chem. 262,7528 (1987); C. Smagula and M. G. Douglas, ibid. 263, 6783 (1988); R. Pfaller, H. F. Steger, J. Rassow, N. Pfanner, W. Neupert, J. Cell Biol. 107, 2483 (1989); R. Pfaller, N. Pfanner, W.
Neupert, J. Biol. Chem. 264, 34 (1989).

21. T. Söllner, G. Griffith, R. Pfaller, N. Pfanner, W. Neupert, Cell 59, 1061 (1989); T. Söllner, R. Pfaller, G. Griffth, N. Pfanner, W. Neupert, in preparation.

22. T. Hase, U. Müller, H. Riezmann, G. Schatz, EMBO J. 3, 3157 (1984).

23. T. Sölliner, R. Pfaller, N. Pfanner, W. Neupert, in preparation.

24. M. Ohba and G. Schatz, EMBO J. 6, 2117 (1987).

25. D. Vestweber, J. Brunner, A. Baker, G. Schatz, Nature 341, 205 (1989)

26. N. Pfanner, M. Tropschug, W. Neupert, Cell 49, 815 (1987)

27. N. Pfanner and W. Neupert, FEBS Lett. 209, 152 (1986); M. Eilers, W. Oppliger G. Schatz, EMBO J. 6, 1073 (1987); W.-J. Chen and M. G. Douglas, Cell 49, 651 (1987); K. Verner and G. Schatz, EMBO J. 6, 2449 (1987).

28. N. Pfanner et al., J. Biol. Chem. 263, 4049 (1988).

29. J. E. Rothman and R. D. Kornberg, Nature 322, 209 (1986)

30. M. Schleyer, B. Schmidt, W. Neupert, Eur. J. Biochem. 125, 109 (1982); S. M Gasser, G. Daum, G. Schatz, J. Biol. Chem. 257, 13034 (1982); D. M. Kolanski, G. Conboy, W. A. Fenton, L. E. Rosenberg, ibid., p. 8467; N. Pfanner and W. Neupert, EMBO J. 4, 2819 (1985).

31. R. E. Kellems, V. F. Allison, R. A. Butow, J. Cell Biol. 65, 1 (1975).

32. D. Vestweber and G. Schatz, ibid. 107, 2037 (1988).

33. N. Pfanner, F.-U. Hart, B. Guiard, W. Neupert, Eur. J. Biochem. 169, 289 (1987).

34. S. Hwang, T. Jascur, D. Vestweber, L. Pon, G. Schatz, J. Cell Biol. 109, 487 (1989).

35. P. Böhni, S. Gasser, C. Leaver, G. Schatz, in The Organization and Expression of the Mitochondrial Genome, A. M. Kroon and C. Saccone, Eds. (Elsevier/North-Holland, Amsterdam, 1980), pp. 323-433; J. G. Conboy, W. A. Fenton, L. E. Rosenberg, Biochem. Biophys. Res. Commun. 105, 1 (1982); P. C. McAda and M. G. Douglas, J. Biol. Chem. 257, 3177 (1982); B. Schmidt, E. Wachter, W. Sebald, W. Neupert, Eur. J. Biochem. 144, 581 (1984).

36. C. Witte R. E Jensen, M. P. Yaffe, G. Schatz, EMBO J. 7, 1439 (1988); R. A. Pollock et al., ibid., p. 3493; R. E. Jensen and M. P. Yaffe, ibid., p. 3863.

37. G. Hawlitschek et al., Cell 53, 795 (1988); H. Schneider, M. Arretz, E. Wachter, W. Neupert, in preparation.

38. J. P. Hendrick, P. E. Hodges, L. E. Rosenberg, Proc. Natl. Acad. Sci. U.S. A. 86, 4056 (1989).

39. M. Nguyen et al., J. Cell Biol. 104,1193 (1987); E. C. Hurt, O. S. Allison, U. Müller, G. Schatz, J. Biol. Chem. 262, 1420 (1987)

40. M. Yang, R. E. Jensen, M. P. Yaffe, W. Oppliger, G. Schatz, EMBO J. 7, 3857 (1988).

41. M. P. Yaffe and G. Schtaz, Proc. Natl. Acad. Sci. U.S.A. 81, 4819 (1984); M. P. Yaffe, S. Ohta, G. Schatz, EMBO J. 4, 2069 (1985)

42. F.-U. Hart, J. Martin, M. Y. Cheng, A. L. Horwich, W. Neupert, unpublished data.

43. U. Schulte et al., Nature 339, 147 (1989); P. Oudshoorn, H. van Steeg, B. W. Swinkels, P. Schoppink, L. A. Grivell, Eur. J. Biochem. 163, 97 (1987); A. Tzagoloff, M. Wu, M. Grivellone, J. Biol. Chem. 261, 17163 (1986).

44. Y. A. Hatef, Annu. Rev. Biochem. 54, 1015 (1985).

45. F.-U. Hartl, B. Schmidt, E. Wachter, H. Weiss, W. Neupert, Cell 47, 939 (1986) F.-U. Hartl, N. Pfanner, W. Neupert, Biochem. Soc. Trans. 15, 95 (1987).

46. F.-U. Hartl, J. Ostermann, B. Guiard, W. Neupert, Cell 51, 1027 (1987)

47. A. P. G. M. van Loon, A. W. Brändli, G. Schatz, ibid. 44, 801 (1986); A. P. G. M. van Loon and G. Schatz, EMBO J. 6, 244I (1987).

48. B. Guiard, EMBO J. 4, 3265 (1985); J. Römisch, M. Tropschug, W. Sebald, H. Weiss, Eur. J. Biochem. 164, 111 (1987)

49. I. Sadler, K. Suda, G. Schatz, F. Kaudewitz, A. Haid, EMBO J. 3, 2137 (1984)

50. S. M. Gasser et al., Proc. Natl. Acad. Sci. U.S. A. 79, 267 (1982); M. Teintze, M. Slaughter, H. Weiss, W. Neupert, J. Biol. Chem. 257, 10364 (1982).

51. G. von Heijne, Eur. J. Biochem. 133, 17 (1983).

52. D. W. Nicholson, R. A. Stuart, W. Neupert, J. Biol. Chem. 264, 10156 (1989) 53. E. Pratje and B. Guiard, EMBO J. 5, 1313 (1986).

54. A. Ohashi, J. Gibson, I. Gregor, G. Schaz, J. Biol. Chem. 257, 13042 (1982).

55. M. Y. Cheng et al., Nature 337, 620 (1989); M. Y. Cheng, F.-U. Hartl, J. Ostermann, A. L. Horwich, W. Neupert, unpublished data.

56. J. Ostermann, A. L. Honwich, W. Neupert, F.-U. Hartl, Nature 341, 125 (1989)

57. R. J. Ellis, ibid. 328, 378 (1987); S. M. Hemmingsen et al., ibid. 333, 330 (1988) T. W. McMullin and R. L. Hallberg, Mol. Cell. Biol. 8, 371 (1988); D. S. Reading R. L. Hallberg, A. M. Myers, Nature 337, 655 (1989); E. G. Hurchinson, W. Tichelaar, G. Hofhaus, H. Weiss, H. K. R. Leonard, EMBO J. 8, 1485 (1989); R. J. Ellis and S. M. Hemmingsen, Trends Biochem. Sci. 14, 339 (1989).

58. E. S. Bochkareva, N. M. Lissin, A. S. Girshovich, Nature 336, 254 (1988); S. Lecker et al., EMBO J. 8, 2703 (1989).

59. H. Koll, B. Guiard, F.-U. Hartl, W. Neupert, in preparation.

60. R. M. Schwartz and M. O. Dayhoff, Science 199, 395 (1978); T. Cavalier-Smith, in Endocytobiology II, W. Schwemmler and H. E. A. Schenk, Eds. (de Gruyter, Berlin, 1983), pp. 265-279; T. Cavalier-Smith, Ann. N.Y. Acad. Sci. 503, 55 (1987).

61. G. Hauska, E. C. Hurt, W. Lockau, Biochim. Biophys. Acta 726, 97 (1983); G. Hauska, W. Nitschke, R. G. Herrmann, J. Bioenerg. Biomembr. 20, 211 (1988).

62. N. Gabellini and W. Sebald, Eur. J. Biochem. 162, 197 (1986).

63. F. Daldal, S. Cheng, J. Applebaum, E. Davidson, R. C. Prince, Proc. Natt. Acad. Sci. U.S.A. 83, 2012 (1986)

64. L. Thöny-Meyer, D. Stax, H. Hennecke, Cell 57, 683 (1989).

65. W. T. Wickner and H. F. Lodish, Science 230, 400 (1985); W. T. Wickner, Biochemistry 27, 1081 (1988); F.-U. Hartl, in Bioelectrochemistry III, B. A. Milazzo, Ed. (Plenum, New York, in press)

66. J. Alt and R. G. Herrmann, Curr. Genet. 8, 551 (1984); G. von Heijne, J. Stepphuhn, R. G. Herrmann, Eur. J. Biochem. 180, 535 (1989).

67. S. Smeekens, C. Bauerle, J. Hageman, K. Keegstra, P. Weisbeek, Cell 46, 365 (1986). 
68. C. Halpin et al., EMBO J. 8, 3917 (1989)

69. U. Harnisch, H. Weiss, W. Sebald, Eur. J. Biochem. 149, 95 (1985); J. D. Beckman et al., J. Biol. Chem. 262, 8901 (1987).

70. G. Voordouw and S. Brenner, Eur. J. Biochem. 148, 515 (1985).

71. K. Mahlke et al., in preparation.

72. A. Tzagoloff and P. Maegher, J. Biol. Chem. 247, 594 (1972); W. Sebald and E. Wachter, FEBS Lett. 122, 307 (1980); N. J. Gay and J. E. Walker, EMBO J. 4, 3519 (1985)

73. A. Baker and G. Schatz, Proc. Natl. Acad. Sci. U.S. A. 84, 3117 (1987).

74. C. J. Ladzunski et al., Biochim. Biophys. Acta 947, 445 (1988); M. E. Beyer, M. H. Beyer, C. A. Lum, V. Pigiet, J. Bacteriol. 169, 2659 (1987).

75. H. Koll, F.-U. Hartl, W. Neupert, unpublished data.

76. P. Nagley et al., Proc. Natl. Acad. Sci. U.S. A. 85, 2091 (1988).

77. G. von Heijne, FEBS Lett. 198, 1 (1986)

78. M. Klingenberg, Ann. N.Y. Acad. Sci. 456, 279 (1985); H. Aquila, T. A. Link, M Klingenberg, EMBO J. 4, 2369 (1985); M. J. Runswick, S. J. Powell, P. Nyren, J. E. Walker, ibid. 6, 1367 (1987).

79. N. Pfanner, P. Hoeben, M. Tropschug, W. Neupert, J. Biol. Chem. 262, 14851 (1987); L. Xingquan, K. B. Frecman, G. C. Shore, ibid. 265, 1 (1990).

80. C. Nolan and F. Margoliash, Annu. Rev. Biochem. 37, 727 (1968)

81. B. Hennig and W. Neupert, Eur. J. Biochem. 121, 203 (1981); D. W. Nicholson, H. Köhler, W. Neupert, ibid. 164, 147 (1987); D. W. Nicholson, C. Hergersberg. W. Neupert, J. Biol. Chem. 263, 19034 (1988); D. W. Nicholson and W. Neupert, Proc. Natl. Acad. Sci. U.S. A. 86, 4340 (1989).

82. A. Rietveld et al., Biochim. Biophys. Acta 818, 398 (1985); R. A. Stuart, D. W.
Nicholson, W. Neupert, Cell 60, 31 (1990).

83. M. E. Drygas, A. M. Lambowitz, F. E. Nargang, J. Biol. Chem. 264, 17897 (1989); M. E. Dumont, J. F. Emst, D. M. Hampsey, F. Sherman, EMBO J. 6 235 (1987)

84. J. Kaput, M. C. Brandriss, T. Prussak-Wieckowska, J. Cell Biol. 109, 101 (1989).

85. G. C. Flynn, T. G. Chappell, J. E. Rothman, Science 245, 385 (1989)

86. C. B. Anfinsen, ibid. 181, 223 (1973); R. Jaenicke, Prog. Biophys. Mol. Biol. 49, 117 (1987); J. E. Rothman, Cell 59, 591 (1989).

87. M. Eilers, S. Hwang, G. Schat, EMBO J. 7, 1139 (1988)

88. H. Dintzis, Proc. Natl. Acad. Sci. U.S. A. 47, 247 (1961)

89. S. Munro and H. R. B. Pelham, Cell 46, 291 (1986); M.-I. Gething K McCammon, I. Sambrook, ibid., p. 939; D. G. Bole, L. M. Hendershot, L. M Keerney, J. Cell Biol. 107, 1558 (1986); E. A. Craig, J. Kramer, J. KosicSmithers, Proc. Natl. Acad. Sci. U.S. A. 84, 4156 (1987); E. A. Craig et al., Mol. Cell. Biol. 9, 3000 (1989).

90. S. T. Hwang and G. Schatz, Proc. Natl. Acad. Sci. U.S. A. 86, 8432 (1989).

91. M. D. Rose, L. M. Misra, J. P. Vogel, Cell 57, 1211 (1989); J. P. Vogel, L. M. Misra, M. D. Rose, in Yeast Cell Biology Abstracts (Cold Spring Harbor Laboratory, Cold Spring Harbor, NY, 1989), p. 97.

92. Abbreviations for the amino acid residues are: $A, A l a ; C, C y s ; D, A s p ; E, G l u ; F$, Phe; G, Gly; H, His; I, Ile; K, Lys; L, Leu; M, Met; N, Asn; P, Pro; Q. Gln; R Arg; S, Ser; T, Thr; V, Val; W, Trp; and Y, Tyr.

93. We thank A. L. Horwich, F. E. Nargang, C. Robinson, J. E. Rothman, G. Schatz, and $\mathrm{G}$. C. Shore for unpublished information. Work from our own laboratory was supported by the Deutsche Forschungsgemeinschaft, SFB 184.

\section{AAAS-Newcomb Cleveland Prize}

\section{To Be Awarded for an Article or a Report Published in Science}

The AAAS-Newcomb Cleveland Prize is awarded to the author of an outstanding paper published in Science. The value of the prize is $\$ \mathbf{5 0 0 0}$; the winner also receives a bronze medal. The current comperition period began with the 2 June 1989 issue and ends with the issue of 25 May 1990.

Reports and Articles that include original research data, theories, or syntheses and are fundamental contributions to basic knowledge or technical achievements of far-reaching consequence are eligible for consideration of the prize. The paper must be a first-time publication of the author's own work. Reference to pertinent earlier work by the author may be included to give perspective.
Throughout the competition period, readers are invited to nominate papers appearing in the Reports or Articles sections. Nominations must be typed, and the following information provided: the title of the paper, issue in which it was published, author's name, and a brief statement of justification for nomination. Nominations should be submitted to the AAAS-Newcomb Cleveland Prize, AAAS, Room 924, $1333 \mathrm{H}$ Street, NW, Washington, DC 20005, and must be received on or before 30 June 1990. Final selection will rest with a panel of distinguished scientists appointed by the editor of Science.

The award will be presented at the 1991 AAAS annual meeting. In cases of multiple authorship, the prize will be divided equally between or among the authors. 